\title{
INOVAÇÃO E INCLUSÃO: UMA INTEGRAÇÃO EM FAVOR DOS ALUNOS DE ESCOLA PÚBLICA NA UNIVERSIDADE
}

\author{
INNOVATION AND INCLUSION: INTEGRATION IN FAVOUR \\ OF PUBLIC SCHOOL STUDENTS IN PUBLIC UNIVERSITY
}

\author{
INNOVACIÓN E INCLUSIÓN: UMA INTEGRACIÓN A FAVOR \\ DE LOS ALUMNOS DE ESCUELA PÚBLICA EN LA UNIVERSIDAD
}

\section{Elisabete Monteiro de Aguiar Pereira ${ }^{l}$}

\begin{abstract}
RESUMO
O texto relata resultados da pesquisa que visou conhecer e avaliar o impacto do Programa de Formação Superior Interdisciplinar (ProFIS) da Universidade Estadual de Campinas, por se tratar de um programa experimental voltado para um grupo diferenciado de alunos, com demandas específicas e com um currículo diferenciado. Como objetivos a pesquisa buscou: - conhecer a visão dos docentes sobre o oferecimento do curso com as especificidades que possui e como lidaram com alunos com distintas demandas e com os desafios pedagógicos de um currículo de formação geral e interdisciplinar; - avaliar o Programa do ponto de vista dos alunos e da coordenação sobre a arquitetura do currículo voltado para uma formação geral e cultural; - levantar os alcances do curso quanto à inclusão social e combate à autoexclusão; - conhecer a avaliação dos alunos sobre a formação recebida para prepará-los academicamente para a continuidade da formação profissional e a atuação como cidadão. A pesquisa se reveste de importância uma vez que a universidade ainda não se conhece como administradora de um curso de formação tão específica como é o objetivo do ProFIS. A metodologia utilizada foi diferenciada para cada um dos aspectos a ser avaliado e para cada grupo de sujeitos. Questionários para alunos, entrevistas para professores e coordenadores. Os resultados demonstram a satisfação dos alunos, as boas considerações feitas ao design do curso pelos professores e coordenadores, a efetiva inclusão que proporciona a esse grupo tão específico de clientela universitária.
\end{abstract}

PALAVRAS-CHAVE: Inovação e inclusão. Universidade pública e inclusão. Educação superior e inovação.

\begin{abstract}
This paper reports results of the research aimed to understand and evaluate the impact of Higher Education Program Interdisciplinary (PROFIS), State University of Campinas, in the case of a dedicated experimental program to a different group of students with specific demands and a differentiated curriculum. As research objectives sought: - know the vision of the teachers on the course offering to the specifics you have and how they coped with students with different demands and the educational challenges of a curriculum of general and interdisciplinary training; - Evaluate the point of view of the program students and coordination of the architecture oriented curriculum for general and cultural education; - Lifting the course reaches as social inclusion and combating self-exclusion; - Know the evaluation of students about the training received to prepare them academically for continuing vocational training and acting as a citizen. The research is of importance since the university is not yet known as a manager of a training course as specific as is the goal of profes. The methodology used was different for each of the aspects to be assessed and for each group of subjects. Questionnaires for students, interviews with teachers and coordinators. The results demonstrate the student satisfaction, good considerations to teachers course design and engineers, the effective inclusion that provides this very specific group of universitária.
\end{abstract}

KEYWORDS: Innovation and inclusion. University public and inclusion. Higher education and innovation.

\footnotetext{
${ }^{1}$ Professora Titular da Faculdade de Educação da Unicamp. Coordenadora do Grupo Internacional de Estudos e Pesquisa sobre Educação Superior- GIPES. ORCID: http://orcid.org/0000-0001-8263-9534. E-mail: eaguiar@unicamp.br

Submetido em: 05/01/2016 - Aceito em: 26/04/2016.

\begin{tabular}{l|l|l|l|l|l|l} 
(C) Rev. Inter. Educ. Sup. & Campinas, SP & v.2 & n.1 & p.175-190 & jan./abr. 2016 & ISSN 2446-9424
\end{tabular}
}




\section{RESUMEN}

El texto relata resultados de la investigación que visó a conocer y evaluar el impacto del Programa de Formación Superior Interdisciplinaria (ProFIS) de la Universidade Estadual de Campinas, por tratarse de un programa experimental direccionado a un grupo diferenciado de alumnos, con demandas específicas y con un currículo diferenciado. Como objetivos la investigación buscó: - conocer la visión de los docentes sobre el ofrecimiento del curso con las especificidades que posee y cómo lidiaron con alumnos con distintas demandas y los desafíos pedagógicos de un currículo de formación general e interdisciplinaria; - evaluar el Programa desde el punto de vista de los alumnos y de la coordinación sobre la arquitectura del currículo vuelto a una formación general y cultural; - levantar los alcances del curso en cuanto a la inclusión social y combate a la autoexclusión; - conocer la evaluación de los alumnos sobre la formación recibida para prepararlos académicamente para la continuidad de la formación profesional y la actuación como ciudadano. La investigación se reviste de importancia puesto que la universidad todavía no se conoce como administradora de un curso de formación tan específica como es el objetivo del ProFIS. La metodología utilizada fue diferenciada para cada uno de los aspectos a ser evaluado y para cada grupo de sujetos. Cuestionarios para alumnos, entrevistas para profesores y coordinadores. Los resultados demuestran la satisfacción de los alumnos, las buenas consideraciones hechas al diseño del curso por los profesores y coordinadores, y la efectiva inclusión que proporciona a ese grupo tan específico de clientela universitaria.

PALABRAS-CLAVE: Innovación e inclusión. Universidad pública e inclusión. Educación superior e innovación.

\section{O design do ProFIS}

O Programa de Formação Interdisciplinar Superior da Unicamp (ProFIS) está sendo desenvolvido desde 2011 como projeto experimental de curso de educação superior de atendimento à política educacional brasileira de formação geral e de inclusão social. Trata-se de um programa inteiramente novo nas políticas de educação superior brasileira. Suas inovações abordam vários aspectos, tais como: planejamento, organização pedagógica, estrutura curricular, seleção de alunos, metodologia, corpo docente, corpo discente, modalidade de oferecimento, formas de apoio pedagógico, financeiro e de assistências aos alunos, sistemática de avaliação longitudinal do curso e de seus egressos.

O ProFIS, por ser o primeiro curso da história da universidade brasileira voltado para uma formação geral, apresenta especificidades que foram um dos principais focos da análise da pesquisa que visou conhecer e avaliar:

- O impacto do curso na universidade, uma vez que o ProFIS trouxe uma nova clientela, sendo oferecido apenas para alunos oriundos de escolas públicas de ensino médio de Campinas;

- A proposta de formação geral interdisciplinar, que tem sido um aspecto inovador na história das universidades brasileiras desde 2005, a partir do oferecimento de Bacharelados Interdisciplinares por universidades federais;

- Levantar a visão dos docentes sobre os acertos do curso, a interdisciplinaridade, a estrutura curricular; os desafios que a nova estrutura curricular trouxe; a avaliação dos alunos, uma vez que são alunos com novas demandas; 
- Conhecer o impacto do programa no próprio ambiente acadêmico e na política educacional da Unicamp para a viabilidade da continuidade do oferecimento do ProFIS.

Para elucidar as questões trabalhadas no projeto de pesquisa se faz necessário uma breve apresentação do ProFIS.

A Universidade Estadual de Campinas - Unicamp há mais de décadas vem desenvolvendo processos de inclusão social que beneficiam alunos de escola pública e estudantes negros, pardos e indígenas, por meio de políticas desenvolvidas pela Comissão de Vestibular. Ao lado dessa política, no ano de 2010 foi aprovado um novo curso denominado "Programa de Formação Interdisciplinar Superior - ProFIS, tendo como finalidade ser um projeto de inclusão voltado exclusivamente para alunos oriundos das 95 escolas públicas de ensino médio da cidade de Campinas.

O oferecimento de um programa totalmente voltado para alunos de escolas públicas, que reconhecidamente recebem um ensino de qualidade comprometida, baseia-se no princípio de que o acesso ao ensino superior público de qualidade representa um dos mais eficientes mecanismos para a alteração do quadro de reprodução das injustiças sociais. Vários estudos sobre acesso à educação superior, como o desenvolvido por Reisberg e Watson (2010) e os de Willians e Swal (2005), Pascarella e Terenzini (2005), apontam que uma formação em nível superior pode permitir aos indivíduos romperem com as barreiras profissionais e sociais impostas pela sua condição socioeconômica. Além do rompimento dessa barreira e do alcance de bens materiais que uma boa colocação no mercado de trabalho proporciona, os estudos demonstram que egressos de ensino superior, oriundos de meio socioeconômico desfavorecidos, não importando o curso feito, são mais felizes, mais saudáveis, democraticamente mais tolerantes e têm menor probabilidade para atividades criminosas. São também os que mais se inclinam para trabalho voluntário, favorecendo assim que outros possam usufruir de um trabalho de boa qualidade.

O design de projeto do ProFIS apresenta dezessete (17) inovações que estão descritas sumariamente a seguir:

a) Política de inclusão por meio do oferecimento de programa voltado exclusivamente para alunos das escolas públicas, Pode-se afirmar esta característica como inovação, uma vez que as demais políticas de inclusão social da Unicamp e de outras universidades brasileiras, oferecem porcentagens de vagas de seus cursos para alunos de escola pública, e dentre essas vagas, é reservada uma percentagem para alunos pretos, pardos e indígenas. O ProFIS não reserva vagas para pretos, pardos e indígenas. Seu objetivo são os alunos do ensino médio público da cidade de Campinas; 
b) O processo de criação e implementação do curso foi desenvolvido por uma Comissão Multidisciplinar, contando com docentes das várias unidades de ensino da Unicamp. Normalmente o planejamento de um curso nas universidades brasileiras é desenvolvido por docentes da área específica. Neste caso, por e tratar do planejamento de um novo curso com a intenção de ser de formação geral e interdisciplinar, essa característica foi observada desde a composição da Comissão de planejamento. Após a elaboração do projeto, este foi apresentado e discutido com docentes e alunos em cada uma das 22 unidades de ensino da universidade e nas diferentes instâncias administrativas da Unicamp;

c) O ProFIS está organizado na forma de curso sequencial, (que é uma modalidade de curso prevista pelo art. 44 da Lei 9394/96 - Lei de Diretrizes e Bases da Educação Nacional), com duração de dois anos e oferece uma formação geral interdisciplinar, isto é, busca o desenvolvimento de habilidades básicas (capacidades de ler, escrever, lidar com números, saber pensar e resolver problemas, trabalhar em grupo) e a ampliação de conhecimentos nas áreas do conhecimento desenvolvidas pela Unicamp - ciências humanas, exatas, biológicas e arte. Sua intencionalidade é possibilitar a abordagem de problemas científicos de modo integrado e a compreensão da ciência como um modo de olhar o mundo. Por meio desses princípios o programa busca desenvolver a formação dos alunos como cidadãos críticos e preocupados com uma sociedade mais justa e ética. Este é um aspecto inteiramente inovador, pois, todos os cursos de ensino superior brasileiro são voltados para uma formação técnica específica;

d) O processo seletivo para o ProFIS não segue o organizado e desenvolvido para a seleção de alunos nos cursos da Unicamp. O processo utiliza as notas do Exame Nacional do Ensino Médio, conhecido pela sigla ENEM, que é um exame aplicado nacionalmente nos egressos do ensino médio. Para o ProFIS pode se candidatar somente os alunos egressos do ensino médio das 95 escolas públicas que fizeram o ENEM do ano em curso;

e) Ter na Unicamp a representação de todas as escolas de ensino médio de Campinas, com no mínimo, um aluno de cada uma das 95 escolas públicas. Para essa representação é selecionado um, ou no máximo, dois alunos da escola, sendo estes os melhores colocados no ENEM. São oferecidas 120 vagas/ano. Essa forma de seleção é uma política de educação que permite a entrada de uma clientela normalmente ausente de universidades mais competitivas como a Unicamp. Desde 2004, a universidade vem desenvolvendo sua política específica de inclusão social por meio do Programa de Ação Afirmativa e Inclusão Social - PAAIS, que passou a beneficiar com um acréscimo de pontos no valor das notas do vestibular os alunos que cursaram integralmente o ensino médio em escola pública no Brasil e, com mais 40 pontos os autodeclarados pretos, pardos e indígenas. Essa política promove, pelo mérito, a inclusão e a diversidade étnica e cultural na universidade e não apenas por critérios econômicos e raciais. Desde a implantação do PAAIS a Unicamp aumentou o índice 
de candidatos oriundos de escolas públicas para 46,6\% em 2016 (CONVEST, 2016). No entanto, essa política não tem impacto em termos de representação das próprias escolas públicas, mas só a de alunos oriundos da escola pública. Com a sistemática de seleção utilizada pelo ProFIS foi imediata a representação das escolas públicas quando da seleção da primeira turma do ProFIS em 2011. Até o oferecimento do ProFIS, mais da metade das 95 escolas públicas da cidade não tinha um aluno matriculado na Unicamp. Parte dos motivos é o de que o ensino oferecido por elas não prepara de forma suficiente para o aluno passar pelas altas exigências do vestibular da universidade, e outra parte pelo fenômeno da autoexclusão, isto é, esses alunos não têm a Unicamp em seus horizontes por se considerarem pouco preparados para o seu vestibular. A política de inclusão utilizando o ENEM e reservando vaga para ao menos um aluno de cada escola resultou na atração de um novo grupo de alunos. Pelos resultados da pesquisa pode se verificar que estes são a primeira geração da família a frequentar o ensino superior;

f) O Corpo Docente do ProFIS é formado por professores das 21 unidades de ensino que compõem a Unicamp, compondo um quadro das diferentes áreas do conhecimento. Este aspecto inovador leva a vários desafios aos professores por trabalharem com colegas e conhecimentos diferentes daqueles que estão acostumados nas suas unidades. Os docentes aprendem a dialogar com concepções e enfoques diversos dos que normalmente trabalham em suas unidades por estarem em contato com mais áreas do conhecimento. Na forma brasileira tradicional de estruturar os cursos de graduação essa integração é impossível, uma vez que os cursos são estanques e o conhecimento é específico não só da área, mas, muitas vezes, de uma subárea como por exemplo: engenharia elétrica, engenharia mecatrônica etc.;

g) Após os dois anos de formação no ProFIS, os alunos podem escolher uma vaga em um dos cursos de graduação dentre as vagas reservadas por cada curso aos egressos do ProFIS. Em média há o oferecimento de 2 vagas para cada curso, no entanto, alguns cursos ampliaram esse número por verificar a boa formação e performance dos egressos do PRoFIS, como é o caso do curso de medicina que hoje já oferece 10 vagas;

h) O desenvolvimento do ProFIS se dá em tempo Integral. O oferecimento do programa em tempo integral (manhã e tarde) objetiva inserir o aluno em amplas atividades da vida acadêmica como aulas teóricas, atividades de cultura geral focadas em questões científicas, sociais, humanas, culturais, econômicas, políticas e éticas, atividades de pesquisa. Embora se tenha no Brasil cursos oferecidos em tempo integral, o objetivo desses cursos não é o de favorecer a formação geral como é a finalidade no ProFIS;

i) Os alunos do ProFIS contam com Atendimento Pedagógico específicos às suas deficiências escolares. Sendo conhecida as deficiências do nosso sistema público de educação média, o ProFIS estruturou um apoio pedagógico para atender às dificuldades particulares de cada aluno. Diagnosticadas as deficiências, os alunos são 
atendidos, no contra turno de suas aulas, por doutorandos da área específica de sua deficiência, com um programa elaborado pelo professor da disciplina e desenvolvido por meio do Programa de Estágio Docente- PED;

j) Política de apoio à permanência no curso. A situação financeira dos alunos de escolas públicas muitas vezes os impede de frequentar curso superior por necessidade de trabalhar e se manter, ou mesmo auxiliar na manutenção da família. Essas carências econômicas são parcialmente atendidas por meio de um efetivo auxílio financeiro, caracterizado por bolsa de estudos, bolsa transporte e bolsa alimentação. A Unicamp reserva recursos para esse fim, entendendo que sem isto os alunos teriam dificuldade de frequentar o ProFIS e o programa não atingiria os seus objetivos. Os alunos ccontam também com o serviço de apoio psicológico, assistência médica, odontológica e jurídica, que são apoios oferecidos a todos os alunos da Unicamp;

k) Para conhecer e avaliar a experiência desenvolvida pelo ProFIS, foi planejado um Programa de Avalição Contínua (PACP) que desenvolve uma sistemática de longo prazo, planejada para um período de dez anos (até 2021), com o objetivo de acompanhar os alunos desde o ingresso no ProFIS, durante os dois anos de curso, no desenvolvimento do curso de graduação e na inserção no mercado de trabalho e inserção social. A execução esta a cargo do Núcleo e Estudos de Políticas Públicas NEPP. Além dos pesquisadores que integram o NEPP a sistemática de avaliação desenvolvida conta com uma Comissão de Orientação e Acompanhamento composta por docentes da Unicamp e pelo Coordenador do ProFIS, garantindo a perspectiva da interdisciplinaridade também nessa fase do programa. O processo é inédito em avaliação de cursos no Brasil por ultrapassar a simples verificação de satisfação de docentes e discentes (CARNEIRO e ANDRADE, 2012). A metodologia de avaliação contempla o acompanhamento dos alunos via dados de desempenho, entrevistas e questionários periódicos desenvolvidos com a coordenação, os docentes e os discentes. A avaliação pretende auxiliar no aperfeiçoamento do ProFIS, na identificação de necessidades para o seu constante aprimoramento, no atendimento às necessidades dos alunos, na verificação da sua capacidade de acompanhar o curso de graduação e avaliar como a formação recebida auxilia o aluno no seu desenvolvimento profissional e na sua inserção social, já que o objetivo da formação geral é proporcionar uma atuação cívica mais engajada nas questões sociais;

1) Formação para a pesquisa. A Iniciação Científica (IC) compõe o currículo do ProFIS e responde ao princípio da formação geral de preparar para a compreensão da produção de conhecimento. A Iniciação Científica é oferecida como uma disciplina, pelo período de um ano e desenvolvida por meio da vinculação do aluno a um projeto de pesquisa supervisionado por um docente das diferentes unidades de ensino da universidade. Os docentes interessados em orientar um aluno do ProFIS inscrevem projeto de pesquisa junto à Coordenação do IC e é o aluno que escolhe o projeto ao qual quer se vincular. No desenvolvimento do projeto, todos os passos da pesquisa 
são vivenciados pelos alunos: revisão bibliográfica, de experimentação prática, de redação de um relatório e de apresentação e defesa dos resultados alcançados;

m) Ao concluir o ProFIS, além do direito de ingressar em um dos 70 cursos oferecidos pela Unicamp, sem passar pelo vestibular, o aluno recebe um Certificado de Conclusão de Curso Sequencial de Complementação de Estudos com a seguinte denominação "Certificado de Formação Interdisciplinar Superior", (UNICAMP, 2014). Esse diploma dá ao aluno a condição de continuar seus estudos em nível superior;

n) Para auxiliar na escolha do curso de graduação, o currículo do ProFIS oferece a disciplina "As Profissões" e apoio do Serviço de Apoio ao Estudante - SAE. Dos cursos de graduação da Unicamp, só não oferecem vagas para o ProFIS os cursos que aplicam prova específica de habilidade como Artes Cênicas, Dança e Música, com exceção do curso de arquitetura que, apesar de ter de prova de habilidades, oferece vaga para o ProFIS. A seleção para as vagas nos cursos de graduação é feita pelo Coeficiente de Rendimento (CRO) do aluno no curso, por ordem decrescente de pontuação. Dada a classificação dos alunos pelo CRO, estes escolhem os cursos de sua preferência. Não são os cursos que escolhem os alunos, mas os alunos que escolhem o curso. O processo de escolha segue a ordem decrescente de $\mathrm{CRO}$, até que sejam contemplados todos os alunos;

o) O ProFIS tem a peculiaridade de estar alocado na Pró-Reitoria de Graduação, isto é, não tem uma unidade que o abriga, uma vez que não é específico de nenhuma delas e não tem uma área de conhecimento dominante. Essa estruturação é uma inovação pois todos os demais cursos têm uma unidade de ensino. A Coordenação do ProFIS é exercida por um professor indicado pelo Pró-Reitor de Graduação. O exercício da coordenação, com coordenadores oriundos de diferentes áreas, demonstra o espírito da interdisciplinaridade proposto para o curso;

p) O ProFIS foi aprovado pelo Conselho Universitário (CONSU) em 9 de setembro de 2010 para início no ano letivo de 2011. A grade curricular é composta de 28 disciplinas oferecidas pelas várias unidades, totalizando 109 créditos, além de 8 créditos eletivos, sendo que $40 \%$ dos créditos correspondem a atividades práticas que ocorrem em sala de aula, laboratórios e em projetos Iniciação Científica. Das 28 disciplinas, 12 foram criadas especialmente para atender ao programa e 16 são disciplinas já existentes na Unicamp, que foram adaptadas ao projeto pedagógico do curso. De forma geral, todos os professores reorganizaram seus cursos adaptando os conteúdos considerando que o objetivo do ProFIS não era o de formar para uma área específica, mas o de favorecer um conhecimento geral e interdisciplinar, e por isso, o conteúdo não deveria ser a reprodução das disciplinas introdutórias oferecidas em cada área. Embora cada uma dessas disciplinas tenha seu propósito, todas desenvolvem alguns aspectos em comum: habilidades de comunicação oral e escrita, raciocínio lógico, formal e abstrato, responsabilidade ética quanto ao meio social e 
ambiental, pensamento crítico, reflexão sobre a complexidade do viver humano, pensamento analítico sobre a cultura e a diversidade cultural.

q) Infraestrutura - a opção foi a de aproveitar toda a infraestrutura física já existente e os alunos do ProFIS têm aulas em vários dos prédios que servem as 22 unidades de ensino da Unicamp, particularmente as salas do Ciclo Básico que têm capacidade para 120 alunos. Quando as aulas são dadas com as turmas divididas em pequenos grupos, como por exemplo para as aulas de inglês, são usadas salas da própria unidade de oferecimento. O mesmo acontece com as aulas que precisam de laboratórios ou outro equipamento, como as de biologia e as de laboratório de informática. Com isso, os alunos do ProFIS têm a oportunidade de circularem pela universidade toda e isto é visto por eles de forma muito positiva. Para a parte administrativa conta apenas com uma secretaria de atendimento aos alunos e docentes.

É importante mencionar que nesse tempo de oferecimento do ProFIS, o programa tem obtido grande reconhecimento tanto internamente como externamente à Unicamp, e recebeu um reconhecimento público do meio educacional concretizado pela premiação obtida em abril de 2013, da Fundação Péter Murányi, de São Paulo que premia casos de inovação na área da educação em toda a América Latina.

\section{Alguns resultados da pesquisa}

Muitos são os resultados alcançados pela ousadia do programa ProFIS e apresentamos a seguir alguns deles.

A) Em relação à representação de escolas públicas na Unicamp, a forma de ingresso usada pelo ProFIS permitiu um aumento de $100 \%$, passando de $45 \%$ para $90 \%$ a representação das escolas públicas de ensino médio da cidade de Campinas. A falta de participação de algumas escolas no próprio ENEM, não permitiu que o ProFIS tivesse a representação de todas as escolas. O escopo de atendimento se reduz às escolas de Campinas por se tratar de um programa experimental que está em avaliação contínua para ser conhecida a sua validade e ser desenvolvido um estudo quanto a viabilidade de ser ampliado o seu atendimento.

A falta da totalidade de representação das escolas públicas elucida que, de forma geral, o alcance da política de inclusão de alunos de escolas públicas no ensino superior usando o ENEM desenvolvida pelas universidades brasileiras, embora tenha um apelo democrático e aparenta ser um fator de oportunidades iguais para os egressos do ensino médio público, não atinge a maioria ou a totalidade dos alunos, por muitas escolas não participarem do exame. Estes dados e os relativos à pontuação dos alunos de escolas públicas no ENEM apontam para a necessidade da melhoria da qualidade de ensino público brasileiro. Qualquer política de inclusão não pode descuidar da qualidade do ensino médio ou permitir que este nível de ensino não cumpra com sua responsabilidade, isto é, a responsabilidade de favorecer aos alunos do ensino médio o conhecimento básico que é necessário a todo cidadão

\begin{tabular}{l|l|l|l|l|l|l} 
(C) Rev. Inter. Educ. Sup. & Campinas, SP & v.2 & n.1 & p.175-190 & jan./abr. 2016 & ISSN 2446-9424 \\
\hline
\end{tabular}


conforme determina a Constituição Brasileira e a Lei de Diretrizes do Ensino Básico- Lei 9394/96.

B) Quanto à distribuição socioeconômica, o levantarmos o nível socioeconômico dos alunos nos 3 anos primeiros anos de oferecimento do programa temos que $6 \%$ pertencem ao nível médio alto (mais de 10 salários mínimos), 7\% ao nível médio (de 5 a 10 salários mínimos), 27\% ao nível médio-baixo (de 3 a 5 salários mínimos) e $61 \%$ ao nível baixo (de 1 a 3 salários mínimos). Estes dados confirmam o acerto da política de auxílio financeiro para os alunos ProFIS como forma de favorecer a permanência destes no curso e demonstram a necessidade dessa política como complementar à política de inclusão ao ensino superior.

Esta distribuição socioeconômica tem forte relação com a média das notas do ENEM obtidas pelos alunos matriculados no ProFIS, lembrando que os matriculados são os que obtiveram os primeiros lugares na classificação do ENEM de suas escolas. Os dados fornecidos pelo Questionário de Matrícula da Diretoria Acadêmica da Unicamp a respeito dos alunos do ProFIS apresentam que a média de notas do ENEM no de ano de 2011, foi de 594,33, em 2012 foi de 586,83 e em 2013 foi 583,65. Observa-se que houve um pequeno decréscimo na média da nota dos alunos de 2011 a 2013. Este dado é importante por fornecer um quadro sobre o nível de conteúdo educacional adquirido por esses alunos no ensino médio. Os dados demonstram que se o critério de seleção fosse apenas as maiores notas no ENEM, como é usado em outras universidades brasileiras, o ProFIS teria alunos de cerca de metade do total de escolas púbicas de Campinas.

C) Em relação à cor ou raça/etnia, embora o processo seletivo do ProFIS não utilize cotas para pretos e pardos, $36 \%$ dos alunos matriculados se auto declaram negros ou pardos, com predominância de pardos. Os brancos somam 64\% brancos. Essa proporção acompanha a proporção entre alunos brancos, pretos e pardos do ensino médio das escolas públicas de Campinas e do Estado de São Paulo, segundo os dados do IBGE/2010. Para Campinas, temos que 61\% estudantes do ensino médio se declaram brancos, 28,1\% pardos e 9,6\% pretos. Para o Est. De São Paulo, $60 \%$ brancos, $33,1 \%$ pardos e $5,9 \%$ pretos.

D) Satisfação dos alunos com o ProFIS. Por ser um curso com muitas inovações e por ter como foco de formação uma educação geral, a avaliação deste aspecto é grande importância para a educação superior brasileira que é totalmente centrada na formação específica para uma área profissional e para um nicho do mercado de trabalho. Considerando que o ProFIS não forma para o mercado de trabalho, mas para uma formação geral do aluno, é interessante apresentar consideração sobre essa ênfase de formação e apontar qual é o grau de satisfação dos alunos com o desenvolvimento do programa. 
A intenção do ProFIs foi a de formar o cidadão-profissional para o mundo do trabalho. Essa preocupação é bastante diferente do que a de formar para o mercado de trabalho. Formar o estudante com ênfase na formação geral, permite que o currículo seja centrado em questões mais amplas e abrangentes de todas as áreas (PEREIRA, 2010).

A formação geral não é uma nova ênfase curricular, pois tem sido uma constante no processo de formação do estudante desde os primórdios da universidade, e é hoje a ênfase de boas universidades como a Universidade Harvard, Cambridge, Oxford e muitas outras universidades, principalmente nos países anglo saxões.

Em termos de formação do aluno, notadamente na contemporaneidade, ela tem sido apontada como uma das contribuições mais valorosas que a universidade pode fazer para o bem do aluno e da sociedade em geral, e é essencial para uma sociedade que se quer livre, democrática e justa (PEREIRA, 2010). Na opinião de Nusbaum (1997) a educação geral retoma Sócrates que dizia que a vida para ter sentido deve ser guiada por um exame interno que é próprio de indivíduos que ultrapassam o terreno estreito da profissionalidade na análise de suas ações. Carvalho (2005, p. 34), expõe que também para Aristóteles a formação geral leva a "uma disposição suscetível de criação acompanhada de razão verdadeira e à capacidade de produzir ideias com raciocínio correto".

Quanto ao enfoque em interdisciplinaridade objetivado pelo ProFIS e respeitado na organização do seu currículo, os defensores da interdisciplinaridade (MORIN, 1999; FAZENDA, 1999; REPKO, 2008) argumentam que abordagens disciplinares para a educação, de forma geral, e para a educação superior em especial, são reducionistas e dividem o conhecimento em partes segmentadas, gerando explicações parcializadas, ao invés de gerar explicações abrangentes dos fenômenos do mundo. Defendem que, ao contrário, o currículo organizado de forma interdisciplinar busca favorecer entendimentos mais completos do mundo social e natural. Para esses autores, ao se favorecer que os alunos trabalhem os problemas em abordagem interdisciplinar, é desenvolvida uma série de habilidades intelectuais como as de resolução de problemas, reflexão fundamentada, avaliação e reorientação do pensamento, síntese e integração. Acredita-se que ao desenvolver a capacidade dos alunos de ver e empregar várias perspectivas, é incentivado o respeito pelas perspectivas dos outros, a vontade e capacidade de questionar suposições sobre o mundo e sobre si mesmos, a expansão de horizontes e de perspectivas, a capacidade de pensar de forma criativa e inovadora. Como resultado, os defensores argumentam que o estudo interdisciplinar é uma excelente preparação para o papel de cidadão e trabalhador em uma sociedade plural, tecnológica e democrática.

Os objetivos da ênfase de formação geral e interdisciplinar do currículo do ProFIS se voltam para a aquisição de conhecimentos nas ciências humanas, ciências da natureza e arte, visando abordagens integradas sobre suas relações com o mundo, meio ambiente e mundo do trabalho, sobre o conhecimento e a compreensão de si mesmos como indivíduos e cidadãos de uma sociedade diversificada, globalizada e em constante mudança. 
A avaliação dos estudantes sobre as contribuições da ênfase curricular em formação geral e interdisciplinar foi feita por meio de questionário, em questão fechada, sobre a contribuição do curso para a aquisição das competências estabelecidas nos objetivos do projeto pedagógico do curso. A construção das alternativas da questão refletiu, de forma geral, os propósitos que a Comissão de Planejamento do ProFIS desenhou para o curso. Para o alcance dos objetivos as atividades curriculares foram planejadas para desenvolver habilidades de comunicação oral e escrita em língua materna e em língua estrangeira; habilidade de raciocínio lógico, formal e abstrato; desenvolvimento de responsabilidade ética quanto ao meio social e ambiental; capacidade de pensamento crítico e analítico sobre a diversidade cultural e a dimensão da complexidade do viver humano nas suas expressões artísticas, científicas, literárias, históricas e culturais.

Foi solicitado aos alunos indicarem sua avaliação sobre a contribuição do curso no desenvolvimento dessas habilidades as quais estavam mencionadas em afirmações para a consideração dos alunos em uma escala valorativa de 1 a 5 , onde 1 representava nenhuma contribuição; 2 uma contribuição baixa; 3 uma contribuição média; 4 uma contribuição alta e 5 uma muito alta contribuição. Os questionários foram aplicados em cada turma no terceiro semestre do curso.

Os resultados demonstraram uma boa avaliação dos alunos. Quanto à contribuição do curso para o desenvolvimento das diferentes competências, em seis delas a porcentagem de respostas foi superior a $60 \%$. A contribuição mais significativa para os alunos foi "apreciar, compreender e respeitar a diversidade" com 77\% das respostas assinaladas na valorização contribuição alta (4) e contribuição muito significativa (5). A segunda competência mais assinalada na escala 4 e 5 foi "adquirir uma educação geral e ampla" com 72\%. Em seguida vieram: "pensar de forma crítica e analítica", com 68\%; "escrever de forma clara e eficaz", com 64\%; "falar de forma clara e eficaz, com 61\%; "desenvolver habilidades interpessoais e trabalho em equipe, com 60\%; formação geral interdisciplinar, $60 \%$.

Quando se compara as turmas, verifica-se que a turma de 2012 teve uma porcentagem mais alta do que a turma de 2011, em duas competências "adquirir uma educação geral ampla" ( $82 \%$ e $72 \%$ respectivamente) e "pensar de forma crítica e analítica" ( $72 \%$ e $68 \%$ ).

Em relação a interdisciplinaridade os alunos identificaram seus benefícios inclusive para a opção sobre o curso de graduação que pretendiam seguir. Estes dados foram apresentados por meio da técnica de pesquisa Grupo Focal desenvolvido com alunos egressos do ProFIS e que frequentavam cursos de graduação, no ano de 2015. Grupo Focal consiste na discussão entre participantes que vivenciam ou têm grande conhecimento no tema foco da pesquisa. A técnica de Grupo Focal proporciona dinamicidade e circularidade dos aspectos da temática e a possibilidade de ser explicitada a diversidade de opiniões. O uso desta técnica nesta pesquisa se deu por representar uma forma de coleta de dados a partir da interação grupal dos egressos do ProFIS e que estavam frequentando cursos de graduação na Unicamp. 
Desse modo, o Grupo Focal permitiu que surgisse um nível reflexivo na discussão, que outras técnicas não conseguem alcançar e permitiu desvelar dimensões de entendimentos que frequentemente permanecem inexplorados pelas demais técnicas de coleta de dados qualitativos.

Percebe-se pela análise qualitativa dos dados, que os alunos têm um bom nível de argumentação para defender o aspecto interdisciplinar do curso, como fica explicitado na fala dos alunos:

\begin{abstract}
Eu sabia que queria algo na área de exatas, mas não sabia o que. Aqui você pode ter contato com todas as áreas. Fiz Iniciação Científica na computação e no último semestre fiz uma disciplina de comutação e esse contato direto ajudou muito a ter a certeza de que era isso que eu queria, uma oportunidade que os alunos do vestibular não têm. (Turma 2011)

Queria muito seguir carreira acadêmica e conversando com a professora de Iniciação Científica, tive a ideia de fazer um trabalho na geologia por meio de um método usado na biologia, o que eu não teria pensado se tivesse feito só biologia ou só geologia. (Turma 2012)
\end{abstract}

A questão da interdisciplinaridade foi também levantada junto aos docentes e na opinião destes, a grade curricular é adequada para o modelo de educação geral interdisciplinar pretendido. Os professores foram consultados sobre a contribuição de sua disciplina para o desenvolvimento de quatro habilidades previstas no projeto pedagógico. A opinião dos professores é a de que todas as habilidades foram cobertas, em maior ou menor grau pelas disciplinas consideradas. A habilidade trabalhada com maior ênfase foi a de raciocínio lógico, em parte devido à maior carga de disciplinas da área de exatas. Também chama a atenção que a habilidade comunicação oral e escrita é a única trabalhada de forma transversal em todas as disciplinas. A habilidade menos reforçada foi a da compreensão das instituições sociais, sendo que quatro disciplinas apontaram que esta habilidade não se aplicava ao programa desenvolvido. Grande parte dos professores percebe uma adequação na grade. Algumas falas exemplificam a visão dos docentes:

\begin{abstract}
A grade é ótima. Os alunos até mesmo pedem cursos extras e cursos de verão da disciplina, porém os professores não têm disponibilidade de horários (Prof. de Ética e Bioética).

Tentaram ver o texto cientifico integrado com outras disciplinas - ex. texto de matemática em inglês. Além disso, houve integração com a professora de leitura e produção de texto. (Profs. de Língua Inglesa).
\end{abstract}

Em consonância com a proposta de interdisciplinaridade, os professores tentaram estabelecer ligações entre as disciplinas. $\mathrm{O}$ conceito de evolução, por exemplo, perpassou várias disciplinas, tais como Evolução, Planeta Terra e Química. Isso deverá se intensificar quanto mais consolidadas forem as disciplinas em termos interdisciplinares de conteúdo e formato. Busca-se, assim, a construção da interdisciplinaridade que se refere à oferta do 
conhecimento, não através de disciplinas separadas, mas enfocando a relação que existe entre as diferentes áreas.

Além da adaptação do conteúdo, os professores adaptaram também a linguagem habitualmente utilizada em sala de aula porque os alunos do ProFIS demonstraram não ter familiaridade com determinados termos e vocabulário. Além disso, os professores se esforçaram em suprir a falta de determinados conhecimentos anteriores necessários à adequada contextualização das ideias, durante as próprias aulas expositivas. Essas foram estratégias que facilitaram muito a compreensão de conceitos e a transmissão de novas ideias a ser captadas pelos alunos do ProFIS, mesmo com lacunas em conhecimentos anteriores.

Os alunos também tiveram que rapidamente se adaptar à nova realidade acadêmica. A adaptação foi em relação às aulas em tempo integral e ao nível de exigência muito superior ao que a maioria estava acostumada, comparando-se com o ensino médio. Os alunos relataram, em algumas ocasiões, o grande esforço que tiveram que mobilizar para conseguir acompanhar todas as disciplinas e lidar com as deficiências de formação. Como em qualquer turma, alguns tiveram mais sucesso que outros.

\section{Considerações finais}

O ineditismo do ProFIS no Brasil é o de oferecer um programa organizado na forma de curso sequencial, de 2 anos, com foco na formação geral e interdisciplinar, o que é raro em curso superior mesmo em outras universidades do mundo. É bastante conhecida a oferta de formação geral, principalmente em universidades americanas e europeias e atualmente pelo ciclo básico das universidades europeias de 45 países que formam o Espaço Europeu de Educação Superior. No entanto, a experiência em oferecer um currículo de forma interdisciplinar ainda é bastante nova na maioria das universidades do mundo e quase inédita nas universidades brasileiras. Esse é um dos maiores desafios do ProFIS ao lado do desafio de receber alunos com nível educacional bastante diversificado, oriundos de escolas públicas boas e outras nem tanto, da cidade de Campinas.

São vários os benefícios esperados do currículo planejado para o ProFIS e pelos dados obtidos na pesquisa pode-se afirmar que grande parte deles estão sendo alcançados, o que demonstra o acerto do oferecimento do curso a essa clientela estudantil específica e o acerto de um possível oferecimento a outras clientelas.

Um dos pontos a ser ressaltado é o esforço e entusiasmo dos professores para o sucesso dos alunos e do ProFIS, lembrando que os professores são oriundos de todas as unidades e que aderem ao ProFIS de forma voluntária. Todas as avaliações dos professores para o curso denotam a crença em seu projeto, o acerto em ser voltado para alunos de escolas públicas, o currículo do curso com disciplinas inéditas organizadas com base nas habilidades consideradas essenciais no projeto pedagógico e a forma de desenvolvê-lo em tempo integral,

\begin{tabular}{l|l|l|l|l|l|l} 
(C) Rev. Inter. Educ. Sup. & Campinas, SP & v.2 & n.1 & p.175-190 & jan./abr. 2016 & ISSN 2446-9424
\end{tabular}


com auxílios financeiro e pedagógico para a permanência dos alunos e atendimento às suas carências.

Os professores percebem o ProFIS como um bom Programa e que deve ser continuado. Para eles, a grade curricular é desafiante tanto para os alunos como para eles e tem muito para contribuir com uma formação geral dos alunos, bem como proporciona uma nova dimensão de trabalho para eles. Quanto aos aspectos positivos e negativos do curso, os professores apontam como aspectos positivos: a interdisciplinaridade; o ingresso na Universidade por meio diferente do vestibular da Unicamp favorecendo a entrada de uma clientela totalmente diferente; o trabalho com um grupo de alunos diferente do que estavam acostumados a atender, trazendo novos desafios ao trabalho docente. Como aspecto negativo apontam que ainda falta articulação entre os professores para trabalharem a interdisciplinaridade de forma mais efetiva.

Apesar dos bons resultados do curso e tomando-se em consideração, principalmente que ele foi planejado como uma política de inclusão, a análise dos dados de desempenho acadêmico dos alunos permite sustentar que se torna necessária a luta pela melhoria da escola pública ao lado do desenvolvimento de políticas de inclusão social, educacional e racial, para que todos os alunos da educação básica brasileira tenham a condição de receber uma adequada formação básica, o que é dever do Estado e direito de todo cidadão brasileiro. Os bons resultados do ProFIS não podem encobrir que muito deve ser feito para, e pela educação brasileira, ao lado de políticas de inclusão educacionais desenvolvidas por universidades no Brasil para compensar a falta de uma boa formação dos alunos oriundos de extratos socioeconômicos mais desprivilegiados.

Os dados da pesquisa demonstram que a questão da autoexclusão e da falta de representação de escolas públicas em boas universidades públicas brasileiras se deve mais à qualidade do ensino público em algumas escolas da educação básica e menos a uma política de ensino reservada à elite econômica ou a uma política de exclusão de determinados grupos minoritários. É a política de pouca atenção, ou de atenção efetiva à educação básica brasileira, que resulta no pequeno número de alunos oriundos de escola pública nas boas universidades públicas e não a falta de condições intelectuais ou a desvantagem cultural que têm os alunos oriundos do nível socioeconômico desfavorecido.

As políticas de inclusão no ensino superior não podem perpetuar o permanente descaso com o ensino na educação básica, a complacência com a falta de professores para várias disciplinas, a negligencia para com a falta de estruturas físicas das escolas e a promoção dos alunos para séries seguintes sem a aquisição de conteúdo.

As políticas de inclusão no ensino superior devem ser aperfeiçoadas por meio de iniciativas de inovação curricular e menos por iniciativas para suprir a falta de formação recebida na educação básica, e as instituições de educação superior devem se organizar para receber e manter os alunos vindos das escolas públicas menos por uma política de

\begin{tabular}{l|l|l|l|l|l|l} 
(C) Rev. Inter. Educ. Sup. & Campinas, SP & v.2 & n.1 & p.175-190 & jan./abr. 2016 & ISSN 2446-9424
\end{tabular}


assistencialismo disfarçada de política de inclusão e mais por serem tão bons estudantes como qualquer outro de instituições privadas.

Um ponto de suma importante a ser ressaltado é o de que não há, nem por parte dos alunos, nem por parte dos professores, uma percepção de que o ProFIS seja um curso de nivelamento, que pretende dar maior base para os alunos ou recuperar o que foi mal desenvolvido no ensino médio. Esse é um resultado extremamente importante e possibilita ao ProFIS realmente cumprir os seus objetivos de formação geral, interdisciplinar, de preparação ampla e cultural, preparando os alunos para a formação profissionalizante no curso de graduação, o que tem sido a forma de estruturação do ensino superior nas melhores universidades americanas, europeias, australianas e canadenses.

\section{Referências}

CARNEIRO, A.M., ANDRADE, C.Y., TELLES, S.M.B.S. Avaliação Continuada do Programa de Formação Interdisciplinar Superior na Unicamp: proposta metodológica. Revista Brasileira de Estudos Pedagógicos, n. 93, p.698-719, 2012.

CARVAlHO, A. P. et. al. Arte Retórica e Arte Poética. 17.ed. Rio de Janeiro: Ediouro, 2005.

CONVEST 2016 - Unicamp Tem recorde de matriculados do ensino público. Disponível em: http://correio.rac.com.br/_conteudo/2016/04/campinas_e_rmc/422027-unicamp-temrecorde-de-matriculados-do-ensino-publico.html. Acesso em 20/04/2016.

MORIN Edgar. Complexidade e Transdisciplinaridade: a reforma da universidade e do ensino fundamental. Natal: Editora da EDUFRN, 1999.

NUSSBAUM, Martha. Cultivating Humanity: A Classical Defense of Reform in Liberal Education. Boston: Harvard University Press, 1997.

PASCARELlA, E. T.; TERENZINI, P.T. How College Affects Students, volume 2, A third Decade of Research. San Francisco, CA: Jossey-Bass, 2005.

PEREIRA, E. M. A. Reforma Curricular da Universidade Harvard: a centralidade da educação geral no século XXI. In: PEREIRA, E.M.A Universidade e Currículo: perspectiva de Educação Geral. Campinas: Mercado de Letras, 2010.

PRÓ-REITORIA DE GRADUAÇÃO. Universidade Estadual de Campinas. Projeto Pedagógico: Programa de Formação Interdisciplinar Superior. 2010b. Disponivel em $<$ http://www.prg.unicamp.br/portal/index.php?option=com_docman\&task=doc_download\&g $\mathrm{id}=200 \&$ Itemid=175\&lang=pt $>$, acesso em 13/05/2011.

REISBERG, Liz; WATSON, David. Igualdade e Acesso nas Universidades. Ensino Superior, Ano 1, n.2, 2010, p. 54-69. 
WILLIAMS, A.; SWAIL, W. Is more better? The impact of postsecondary education on the economic and social well-being of American society. Washington, DC: Educational Policy Institute, Inc. 2005. 